\title{
Assessment of factors associated with Tobacco smoking among patients with pulmonary TB attending health facilities in Rwanda: A case control study
}

\section{Patrick Migambi}

Rwanda Biomedical Center

Augustin Dushime

Rwanda Biomedical Center

Prosper Karame

Rwanda Biomedical Center

Murego Nsabimana

Rwanda Biomedical Center

Muhammed Semakula

Rwanda Biomedical Center

Pacifique Ndishimye

Rwanda Biomedical Center

Ladislas Nshimiyimana

Rwanda Biomedical Center

Leopold Bitunguhari

University of Rwanda, Kigali Teaching Hospital

Francine Birungi ( $\sim$ birufrance@yahoo.fr)

University of Rwanda

Mwumvaneza Mutagoma

Ministry of Health

\section{Research Article}

Keywords: Tuberculosis, Smoking, Pulmonary, Factors

Posted Date: September 29th, 2021

DOl: https://doi.org/10.21203/rs.3.rs-930149/v1

License: (9) This work is licensed under a Creative Commons Attribution 4.0 International License. Read Full License 
Page 2/17 


\section{Abstract}

Introduction

The World Health Organization reported that one third of global population was tobacco smoker. In countries with a high tuberculosis burden, a big proportion was attributed to tobacco smoking. In the general population of Rwanda, the prevalence of tobacco smoking was higher among males (14\%) compared to females (3\%). We conducted a second analysis to assess factor associated with tobacco smoking among patient with TB attending Health Facilities.

Methodology

A retrospective case-control study in Centres of Diagnosis and Treatment of tuberculosis (CDT). Cases were patients with bacteriological TB confirmation; controls were persons with signs and symptoms without TB confirmation. Proportions and logistic regression were used in data analysis.

Results

The total number of tobacco smokers was 680 . Among tobacco smokers, $88.1 \%$ tobacco smokers were males, $94.3 \%$ tobacco smokers had at least 25 years old and $64.6 \%$ were living in union. By education, $84.9 \%$ tobacco smokers were illiterate or attained primary school. Almost all tobacco smokers $(97.0 \%)$ ever drunk alcohol while $67.9 \%$ used illicit drugs and $25.3 \%$ had low BMI ( $\leq 18.5)$ with increased proportion among cases (29.1\%). A proportion of $38.3 \%$ in tobacco smokers had history of imprisonment. In multivariable logistic regression data analysis, males compared to females (aOR $=3.49[95 \% \mathrm{Cl}: 1.76-$ 6.94]), ever drunk alcohol compared to never drank alcohol ( $\mathrm{aOR}=6.39[95 \% \mathrm{Cl}: 2.67-15.31])$ and ever used illicit drugs compared to never used illicit drugs ( $\mathrm{aOR}=9.89[95 \% \mathrm{Cl}: 3.87-25.25])$ were associated with high odds of tobacco smoking. In addition, illiterate people or people who attained only primary school education level compared to people having primary education level and above $(\mathrm{aOR}=$ $0.39[95 \% \mathrm{Cl}: 0.23-0.69])$ were associated with low odds of tobacco smoking.

Conclusion

Tobacco smoking is common in pulmonary TB patients. Males were more likely using tobacco smoking compared to females. Alcohol drinkers and illicit drug users were associated to tobacco smoking. A campaign on tobacco cessation, focusing on males, should be conducted in the general population starting by people on TB treatment.

\section{Introduction}

World Health Organization (WHO) reported that $33.3 \%$ of the global population was tobacco smokers(1). Comparing the WHO regions, African region is the less affected by tobacco use. It was estimated at $18.5 \%$ in 2000 in African Region, it decreased at 13.5\% in 2015, and it is expected to decrease at $12.3 \%$ in 2020 and at $11.2 \%$ in 2025(1). The highest prevalence of tobacco smoking was reported in the South- 
East Asia region, where this prevalence was $46.6 \%$ in 2015, it is expected be $27.9 \%$ in 2020 and $25.1 \%$ in 2025(1). There is a kind of tobacco smoking culture in many countries(2). The prevalence of tobacco smoking varies according to countries and demographic characteristics, such as gender, age, race and other(2). The culture component of tobacco smoking was reported in Nigeria, where in marriage ceremony, when one is giving a daughter, tobacco is among the requirements to provide to the family of the daughter(3). A systematic review revealed that the number of tobacco smoking-related deaths increased in African countries(4). However, other studies showed that tobacco smoking-related deaths increased from around 150,000 in 1990 to over 215,000 deaths in 2016(4). In 2016, a research reported that among people over 15 years living in 32 high TB-burden countries, the proportion of TB incidence attributable to tobacco smoking was $19.6 \%$, varying from a country to another(5). The country-specific TB disease attributable to tobacco was $4.7 \%$ in Nigeria while it was $31.6 \%$ in Russia(5). It was reported that tobacco smoking-related death was observed in all African regions, with the highest number of deaths in Eastern Africa(4). According to a cross-sectional study conducted in Ethiopia and Kenya, the prevalence of tobacco smoking among Ethiopian men increased significantly from 8.5\% in 2005 to $11.7 \%$ in 2014 (pvalue $<0.001$ ), while in Kenya, it significantly decreased from $22.9 \%$ in 2003 to $17.0 \%$ in 2014 (p-value < 0.001)(6). In Rwanda the Demographic Health Survey conducted in 2015 showed that the prevalence of any kind of tobacco smoking was lower compared to any prevalence mentioned in other African countries. This prevalence in Rwanda was much higher among men (14\%) compared to women (3\%)(7).

When there is an association between tobacco smoking and pulmonary TB, the situation worsens for pulmonary safety. Sometimes, tobacco smoking can jeopardize TB treatment outcomes. In a case control study conducted in Iran, Alavi-Nain et al. demonstrated a strong association between tobacco smoking and pulmonary TB ( $p$-value $<0.001)(8)$. A study conducted in Georgia showed that there was a poor outcome of TB treatment among people who were tobacco smokers(9). Also, a current or past history of tobacco smoking was positively associated with TB treatment failure and death in an Indian cohort study(10). Moreover, tobacco smoking during breastfeeding was significantly associated to TB transmission to the child compared to non-exposed children(11). This study published that the tuberculin skin test was more positive in exposed children than unexposed children(11).

Factors associated with tobacco smoking among pulmonary TB patients were identified in a number of studies. In Spain, males patients, alcohol users, patients using illicit injecting drugs and poverty were associated with a high odds of tobacco smoking(12). In African countries the identified factors were age, gender, level of education and marital status and employment status(13)(14)(15),

In this study we aimed to assess the factors associated with tobacco smoking among pulmonary TB patients.

\section{Methods}

\section{Study design}


A retrospective case-control study, carried out by the Rwanda Biomedical Centre-TB\&ORD division through its Centres for Diagnosis and Treatment (CDTs) in Rwanda. This study is a secondary data analysis using a data base abstracted a data base of a study carried out from June to December 2017among participants aged 15 or over.

\section{Study population and inclusion criteria}

Cases were defined as patients aged 15 or over who had a positive TB test (confirmation of diagnosis was done through a sputum microscopy test or a GeneXpert test in the past six months). Controls were defined as any person aged 15 or over who attended the same clinics as the case during the same period who was presumptive TB patient (with clinical signs) with no TB diagnosis made by a clinician. The study team located cases from TB registers, contacted them via phone calls, invited and appointed them for interview. A take all approach has been used for the recruitment of cases. In case of refusal to participate, the case was documented and replaced by another eligible participant. For the control group, a random selection was applied to replace any participant who would refuse to participate. The patients with impaired decision-making capacity due to mental health conditions, children under 15 years of age and prisoners were not considered for this study. A Structured questionnaire translated from English to Kinyarwanda was used for interview. For both cases and controls, face-to-face interviews were conducted by trained healthcare providers.

\section{Study site}

The study enrolled participants from CDTs/Health Centres in Rwanda. Thirty-nine CDTs in Health centres were included in the study. Referral Hospitals and prisons were not included in the study because they don't serve a homogenous population.

\section{Sample size calculation}

The minimum sample size was calculated basing on simulation approach and controls (free of TB), we considered a matching of controls with cases for sex and age group. We used a simulation approach to identify the adequate sample size with appropriate power (the probability of finding an effect if it is real). The probability of finding an effect if it is real $(1-\beta)$ was set to $80 \%$; we set a series of 1.2 to 2.5 to detect the Odds Ratio. Each case was given 3 controls (Design 1:3) and we set a series of proportion from 0.01 to 0.9 to calculate the proportion of exposed in the control group $(\lambda)$. The minimum sample size required from the above estimates was 503 cases. From this sample size, we added $20 \%$ for non-response rate; therefore, the sample size of TB cases was 629 cases. We then recruited 3 matched controls for each case recruited totalizing 1887 controls and making a total of 2516 participants.

In order to get at least the power of $80 \%$, we assumed Odds Ratio of 1.5 and proportion of exposed in the control group $(\lambda)$ to be 0.5 . The sample distribution per province and HF was calculated basing on the probability proportional to size (PPS) sampling. A two stages calculation of the weight was applied. In the first stage, the weights has been chosen to compensate for the effect that health facilities do not have 
the same size where is the sampling probability of each cluster, while for the second stage, weights have been used to compensate for the effect that target groups of participants do not have the same number of individuals.

\section{Data collection method}

Study team members received training on data collection tool, ethics and protection of human subjects. Data collectors were also trained to ascertain and document participant eligibility, provide eligible patients with study information, obtain signed informed consents, conduct participant interviews, and provide collected data to the data manager for back up. Prior to the interviews, data collectors obtained signed consent forms from cases and control groups. Interviews were conducted in a secured private place. A structured questionnaire was completed matching one case to three controls. Once all expected cases responded to the questionnaires and matched controls interviewed at the selected sites, the sampling process was ended.

\section{Data management and analysis}

For quality assurance purposes, Access programme-based questionnaires have been used. Every participant had a unique study identification code. Signed informed consents were obtained from participants and stored in a lock and key protected location in RBC under supervision of the Principle Investigator $(\mathrm{PI})$ of the study. A dedicated data manager was responsible for data entry and cleaning processes. Data analysis was performed in MS Excel and Stata version 13.1 (Stata Statistical Software: Release 13. College Station, TX: StataCorp LP). For descriptive statistics, variables were tabulated and subsequent proportions analysed by age, sex, frequencies, percentage, medians and inter-quartile ranges (IQR). In multivariable logistic regression, the dependent variable was tobacco smoking. Sociodemographic and other variables were dependent variables. Differences were considered statistically significant with $p<0.05$.

\section{Ethical considerations}

The informed consent process was completed prior to conducting the interviews. The information sheet was provided and read to participant and signed consent form obtained following voluntarily agreement of participant. Participants were free to withdraw from the study at any moment without any prejudice. All interviews were conducted in private locations to ensure confidentiality. Data collectors were trained on data collection tools, ethical considerations, privacy and confidentiality. The approval of the study and study instruments were obtained from the National Health Research Committee and the Rwanda National Ethics Committee.

\section{Results}

The total number of tobacco smokers in the current study was 680 . 
Table 1 displays the description of the study population by socio-demographic characteristics. Among all the registered tobacco smokers in the study, 223(32.8\%) were recruited from pulmonary TB patients and $88.3 \%$ of them were males. Similarly, $88.0 \%$ of the tobacco smokers were males in the control group. More than $93.0 \%$ of the tobacco smokers were aged 25 or over in both the pulmonary TB cases and control groups. The cases had more underweight tobacco smokers $(29.1 \%)$ than the control group (23.4\%). Furthermore, pulmonary TB cases were found to have higher records of history of imprisonment than the control group with $43.2 \%$ and $35.8 \%$, respectively. Considering HIV status, $27.9 \%$ of TB cases and $14.0 \%$ of control group were HIV positive. 
Table 1

Description of tobacco smokers by socio-demographic characteristics

\begin{tabular}{|c|c|c|c|c|c|c|}
\hline & Control & & Cases & & Total & \\
\hline Socio-demographic characteristics & $\mathbf{N}$ & $\%$ & $\mathbf{N}$ & $\%$ & $\mathbf{N}$ & $\%$ \\
\hline Total & 457 & & 223 & & 680 & \\
\hline \multicolumn{7}{|l|}{ Sex } \\
\hline Male & 402 & 88.0 & 197 & 88.3 & 599 & 88.1 \\
\hline Female & 55 & 12.0 & 26 & 11.7 & 81 & 11.9 \\
\hline \multicolumn{7}{|l|}{ Age group } \\
\hline $15-24$ & 28 & 6.1 & 11 & 4.9 & 39 & 5.7 \\
\hline$\geq 25$ & 429 & 93.9 & 212 & 95.1 & 641 & 94.3 \\
\hline \multicolumn{7}{|l|}{ Marital status } \\
\hline Currently living in union (Married + Cohabitating) & 310 & 68.1 & 128 & 57.4 & 438 & 64.6 \\
\hline $\begin{array}{l}\text { Not currently living in union (Single + Separated + } \\
\text { Widowed + Divorced) }\end{array}$ & 145 & 31.9 & 95 & 42.6 & 240 & 35.4 \\
\hline \multicolumn{7}{|l|}{ Education level } \\
\hline None/Primary & 383 & 83.8 & 194 & 87.0 & 577 & 84.9 \\
\hline Above primary & 74 & 16.2 & 29 & 13.0 & 103 & 15.1 \\
\hline \multicolumn{7}{|l|}{ Occupation } \\
\hline Student & 5 & 1.1 & 0 & 0 & 5 & 0.7 \\
\hline Unemployed & 30 & 6.6 & 18 & 8.1 & 48 & 7.1 \\
\hline Employed & 8 & 1.8 & 2 & 0.9 & 10 & 1.5 \\
\hline Farming & 262 & 57.3 & 116 & 52.0 & 378 & 55.6 \\
\hline Services and Sales workers & 9 & 2 & 13 & 5.8 & 22 & 3.2 \\
\hline Unskilled manual workers & 31 & 6.8 & 20 & 9.0 & 51 & 7.5 \\
\hline Skilled manual workers* & 20 & 4.4 & 10 & 4.5 & 30 & 4.4 \\
\hline Others ${ }^{\star \star}$ & 92 & 20.1 & 44 & 19.7 & 136 & 20 \\
\hline \multicolumn{7}{|c|}{ *Skilled manual workers: were defined as all workers with formal training working as professionals } \\
\hline \multicolumn{7}{|c|}{${ }^{\star \star}$ Others: was defined as all workers - non-professionals } \\
\hline$\star \star \star$ Ubudehe: means social-economic categories in & vanda & & & & & \\
\hline
\end{tabular}




\section{Ubudehe categories}

Ubudehe Category 1

Ubudehe Category 2

Ubudehe Category 3

Unknown

Alcohol drinking

Never

Ever

BMI

$<18.5$ (Underweight)

18.5-24.9 (Normal)

25-29.9 (Overweight)

$>=30$ (Obese)

HIV status

Negative

Positive

Illicit drugs

Yes

No

Homeless

Yes

No

\section{Diabetes}

Yes

No
98

161

157

40

13

440

107

314

34

2

392

64

139

315

116

339
$21.5 \quad 36$

$35.3 \quad 91$

$34.4 \quad 51$

$8.8 \quad 45$

$2.9 \quad 7$

$97.1 \quad 212$
$16.1 \quad 134$

$40.8 \quad 252$

$22.9 \quad 208$

$20.2 \quad 85$

$3.2 \quad 20$

$\begin{array}{lll}96.8 & 652 & 97.0\end{array}$

19.7

37.1

30.6

12.5

3.0




\begin{tabular}{|lllllll|}
\hline & Control & \multicolumn{3}{c}{ Cases } & Total \\
\hline HTA & & & & & \\
\hline Yes & 17 & 3.7 & 3 & 1.3 & 20 & 2.9 \\
\hline No & 440 & 96.3 & 220 & 98.7 & 660 & 97.1 \\
\hline Asthma & & & & & & \\
\hline yes & 2 & 0.4 & 0 & 0 & 2 & 0.3 \\
\hline No & 455 & 99.6 & 223 & 100 & 678 & 99.7 \\
\hline History of imprisonment & & & & & & \\
\hline yes & 163 & 35.8 & 96 & 43.2 & 259 & 38.3 \\
\hline no & 292 & 64.2 & 126 & 56.8 & 418 & 61.7 \\
\hline Living in a ventilated House & & & & & & \\
\hline Yes & 317 & 69.5 & 133 & 61.0 & 450 & 66.8 \\
\hline No & 139 & 30.5 & 85 & 39.0 & 224 & 33.2 \\
\hline$*$ Skilled manual workers: were defined as all workers with formal training working as professionals \\
\hline$* *$ Others: was defined as all workers - non-professionals & & & & & \\
\hline$* * *$ Ubudehe: means social-economic categories in Rwanda & & & & & \\
\hline
\end{tabular}

Globally, $88.1 \%$ tobacco smokers were males, $94.3 \%$ tobacco smokers had at least 25 years old and $64.6 \%$ were living in union. By education, $84.9 \%$ tobacco smokers were illiterate or attained primary school education level. The majority of tobacco smokers were farmers (55.6\%) and $33.2 \%$ of the tobacco smokers were living in non-ventilated house. Almost all tobacco smokers (97.0\%) ever drunk alcohol while $67.9 \%$ used illicit drugs and $25.3 \%$ had low BMI ( $\leq 18.5)$. A proportion of $38.3 \%$ of tobacco smokers had history of imprisonment (Table 1 ).

Table 2 shows factors associated with tobacco smoking among patients attending HF with sign and symptoms of TB. In bivariate logistic regression data analysis, respondents belonging to male gender, having 25 years old or above, having none or primary education level, belonging to Ubudehe (socioeconomic) category one or two, alcohol drinker, using illicit drug, homeless, experienced a history of imprisonment and living in a non-ventilated house were associated with high odds of tobacco smoking among TB patients ( $p$-value $<0.05$ ). 
Table 2

Factors associated with tobacco smoking in pulmonary TB patients in Rwanda

\begin{tabular}{|c|c|c|c|c|c|c|}
\hline & Bivariate & & & Multivariable & & \\
\hline Socio-demographic characteristics & P-value & COR & $95 \% \mathrm{Cl}$ & P-value & aOR & $95 \% \mathrm{Cl}$ \\
\hline \multicolumn{7}{|l|}{ Sex } \\
\hline Male & 0.000 & 4.56 & $\begin{array}{l}{[2.5-} \\
8.31]\end{array}$ & 0.001 & 3.49 & $\begin{array}{l}{[1.76-} \\
6.94]\end{array}$ \\
\hline Female & & 1 & & & 1 & \\
\hline \multicolumn{7}{|l|}{ Age group } \\
\hline $15-24$ & & 1 & & & 1 & \\
\hline$\geq 25$ & 0.003 & 3.98 & $\begin{array}{l}{[1.67-} \\
9.49]\end{array}$ & 0.068 & 2.75 & $\begin{array}{l}{[0.93-} \\
8.16]\end{array}$ \\
\hline \multicolumn{7}{|l|}{ Marital status } \\
\hline $\begin{array}{l}\text { Currently living in union (Married + } \\
\text { Cohabitating) }\end{array}$ & & 1 & & & & \\
\hline $\begin{array}{l}\text { Not currently living in union } \\
\text { (Separated + Widowed + Divorced) }\end{array}$ & 0.513 & 0.88 & $\begin{array}{l}{[0.6-} \\
1.29]\end{array}$ & & & \\
\hline \multicolumn{7}{|l|}{ Education level } \\
\hline None/Primary & 0.000 & 3.46 & $\begin{array}{l}{[2.04-} \\
5.87]\end{array}$ & 0.002 & 2.53 & $\begin{array}{l}{[1.45-} \\
4.41]\end{array}$ \\
\hline Above primary & & 1 & & & 1 & \\
\hline \multicolumn{7}{|l|}{ Ubudehe categories } \\
\hline Ubudehe Category 1 & 0.009 & 2.12 & $\begin{array}{l}{[1.16-} \\
3.86]\end{array}$ & 0.079 & 1.89 & $\begin{array}{l}{[0.93-} \\
3.84]\end{array}$ \\
\hline Ubudehe Category 2 & 0.010 & 1.82 & $\begin{array}{l}{[1.17-} \\
2.85]\end{array}$ & 0.059 & 1.48 & $\begin{array}{l}{[0.99-} \\
2.22]\end{array}$ \\
\hline Ubudehe Category 3 & & 1 & & & & \\
\hline Unknown & 0.005 & 2.89 & $\begin{array}{l}{[1.42-} \\
5.88]\end{array}$ & 0.136 & 1.78 & $\begin{array}{l}{[0.83-} \\
3.83]\end{array}$ \\
\hline \multicolumn{7}{|l|}{ Alcohol drinking } \\
\hline Never & & 1 & & & 1 & \\
\hline Ever & 0.000 & 15.90 & $\begin{array}{l}{[6.76-} \\
37.39]\end{array}$ & 0.000 & 6.39 & $\begin{array}{l}{[2.67-} \\
15.31]\end{array}$ \\
\hline BMI & & & & & & \\
\hline
\end{tabular}




\begin{tabular}{|c|c|c|c|c|c|c|}
\hline & Bivariate & & & Multivariable & & \\
\hline < 18.5 (Underweight) & 0.706 & 0.91 & $\begin{array}{l}{[0.56-} \\
1.49]\end{array}$ & & & \\
\hline 18.5-24.9 (Normal) & & 1 & & & & \\
\hline 25-29.9 (Overweight) & 0.964 & 0.98 & $\begin{array}{l}{[0.45-} \\
2.15]\end{array}$ & & & \\
\hline$>=30$ (Obese) & & 1 & & & & \\
\hline \multicolumn{7}{|c|}{ Ever used modern contraception } \\
\hline Yes & & 1 & & & & \\
\hline No & 0.145 & 2.13 & $\begin{array}{l}{[0.76-} \\
5.95]\end{array}$ & & & \\
\hline \multicolumn{7}{|l|}{ HIV status } \\
\hline Negative & & 1 & & & & \\
\hline Positive & 0.128 & 1.51 & $\begin{array}{l}{[0.88-} \\
2.56]\end{array}$ & & & \\
\hline \multicolumn{7}{|l|}{ Illicit drugs } \\
\hline Yes & 0.000 & 15.56 & $\begin{array}{l}{[6.59-} \\
36.72]\end{array}$ & 0.000 & 9.89 & $\begin{array}{l}\text { [3.87- } \\
25.25]\end{array}$ \\
\hline No & & 1 & & & 1 & \\
\hline \multicolumn{7}{|l|}{ Homeless } \\
\hline Yes & 0.000 & 3.24 & $\begin{array}{l}{[1.92-} \\
5.46]\end{array}$ & 0.778 & 1.12 & $\begin{array}{l}{[0.49-} \\
2.56]\end{array}$ \\
\hline No & & 1 & & & 1 & \\
\hline \multicolumn{7}{|l|}{ Diabetes } \\
\hline Yes & 0.187 & 0.45 & $\begin{array}{l}{[0.13-} \\
1.51]\end{array}$ & & & \\
\hline No & & 1 & & & & \\
\hline \multicolumn{7}{|l|}{ History of imprisonment } \\
\hline yes & 0.007 & 2.90 & $\begin{array}{l}{[1.36-} \\
6.2]\end{array}$ & 0.551 & 1.21 & $\begin{array}{l}{[0.63-} \\
2.32]\end{array}$ \\
\hline no & & 1 & & & 1 & \\
\hline \multicolumn{7}{|l|}{ House ventilated } \\
\hline Yes & & 1 & & & 1 & \\
\hline
\end{tabular}




\begin{tabular}{|lllllll|}
\hline & Bivariate & \multicolumn{5}{c|}{ Multivariable } \\
\hline No & 0.002 & 2.65 & $\begin{array}{l}{[1.47-} \\
\text { 4.76] }\end{array}$ & 0.056 & 1.91 & {$[0.98-$} \\
& & & & & $3.71]$ \\
\hline
\end{tabular}

In multivariable logistic regression data analysis, after adjusting variables, males compared to females $(\mathrm{aOR}=3.49[95 \% \mathrm{Cl}: 1.76-6.94])$, illiterate people or those who attained only the primary school education level compared to people having primary school level and above $(\mathrm{aOR}=2.53$ [95\% $\mathrm{Cl}$ : [1.45-4.41]), ever drunk alcohol compared to never drank alcohol (aOR = 6.39[95\% Cl:2.67-15.31]); and ever used illicit drugs compared to never used illicit drugs $(\mathrm{aOR}=9.89[95 \% \mathrm{Cl}: 3.87-25.25])$ were associated with high odds of tobacco smoking.

\section{Discussion}

The high proportion of tobacco smokers was found among males, alcohol drinkers and illicit drug users. People with no formal education and those who attained only the primary school education level were more likely tobacco smoking than people with education above primary school education level.

Our study found that males were more tobacco smoking than the females (aOR $=3.49[95 \% \mathrm{Cl}: 1.76-$ 6.94]). According to WHO report, the prevalence of tobacco smoking was decreasing from $50.0 \%$ in 2000 to $37.5 \%$ in 2020; and it is expected to decrease at $35.1 \%$ in 2025 among males(1). The same report estimated that the prevalence of tobacco use among females was quite low. It was estimated at $16.7 \%$ in 2000 , then expected to decrease at $8.0 \%$ in 2020 and $6.7 \%$ in 2025(1). A multi-disciplinary study conducted in 2000 in many countries, showed that the prevalence of tobacco smoking varied from 17$64 \%$ among men, while it varied from 1-42\% among women(2). For instance, in China, there was a predominance of tobacco smoking among men compared to women, with a tobacco smoking prevalence of $63 \%$ among men, while it was $4 \%$ among women(2). Higher tobacco smoking in females was related to the Western culture and life style as reported by different authors $(2,16)$. A systematic review study conducted in sub-Sahara African countries showed that tobacco use is most frequently found in males; and the study showed that in females, the tobacco smoking behaviour was linked with high income countries(4). Findings from a study conducted in China among TB patients indicated that tobacco smoking behaviour was more related to males than to females(17). A similar study conducted in Spain found that males were highly associated with tobacco smoking than females $(\mathrm{aOR}=2.26[95 \% \mathrm{Cl}: 1.97-$ 2.60])(12). In South Africa, male gender was found to be associated with tobacco smoking among TB patients(18). Wessels et al, in another study reported that in a tuberculosis specialized hospital in SouthAfrica, among tuberculosis patients, men were significantly tobacco smoking than women(19). The difference of tobacco smoking behaviour by gender was reported in a study conducted in the United State of America(20). A recent study conducted in Rwanda in 2019 reported that males were more likely to tobacco smoke than females(15,(21). In the traditional Rwanda, tobacco smoking was a social value and associated with culture norms where males were allowed to smoke even in public events. By education level, our study revealed that illiterate people or primary school education level were likely to smoke more 
$(\mathrm{aOR}=2.53$ [95\% Cl: $[1.45-4.41])$ compared to people with more that primary school education level. The same, a study conducted in South Africa found that people who completed high education were likely to smoke less (18); another study mentioned above conducted in a tuberculosis specialized hospital above, authors reported that tuberculosis was associated with lower education level(19); and a similar study found that good academic performance was associated with non-tobacco smoking(16). This is complemented by findings from China where people with high education were tobacco smoking less compared to people with non-formal education(22). Likewise, results from a study conducted in rural settings in Uganda found similarly found that people with any education level were less tobacco smoking than people without any form of education level (14). In contrast, results from a study conducted in Kenya, people who attained high school education level and above were likely to smoke more than people with lower education level(23). Tobacco smoking by education level differs from a region to another but it decrease globally with the level of education. The difference between tobacco use in different countries shows that tobacco smoking could be related to socio-cultural norms. Even in Rwanda, tobacco smoking was among cultural values, where men could smoke in cultural ceremonies. Our study showed that alcohol drinking was associated with high odds of tobacco smoking ( $\mathrm{aOR}=6.39[95 \% \mathrm{Cl}: 2.67-15.31])$. The association of illicit drug use with high odds of tobacco smoking among TB patients was observed in our study (aOR $=9.89[95 \% \mathrm{Cl}: 3.87-25.25]$ ). This study corroborates the findings from a study conducted in Malaysia which reported that alcohol drinking was associated with high odds of tobacco smoking(17).

The current research is however subject to several limitations. The analysis was solely based on secondary data analysis. This study has not explicitly categorized different types of tobacco smoking and therefore it combines all type of tobacco smoking including cigarette, water pipe, pipe and so on) as one variable of tobacco smoking. Passive tobacco smokers were not captured in this study. Daily consumption of tobacco and the type of tobacco used were not quantified. For this very reason, we did not intend to capture all factors associated with tobacco smoking. The information provided by the study participants was a self-report with possibility of response bias when collecting self-reported data in healthcare settings. There was no way to verify the veracity of the information. This study shows an epidemiological view of association between tobacco smoking and above-mentioned factors but cannot show causality, however it is informative to decision makers and health providers.

\section{Conclusion And Recommendations}

Generally, tobacco smoking is still a common behaviour in the general population and particularly in pulmonary TB patients. Tobacco smoking is among the leading factors of lung diseases and negatively impacts the outcomes of TB treatment. Our study found that males were more likely to engage in tobacco smoking compared to females. Lower education level in some countries and higher education level in other countries were associated with tobacco smoking. High odds of tobacco smoking were associated with being alcohol drinkers and illicit drug users. 
The community education and awareness campaigns on tobacco cessation should be conducted in the general population starting by people on TB treatment. Tobacco smoking cessation should particularly emphasize on males.

\section{Abbreviations}

aOR

Adjusted odds ratio CDT:Centres of Diagnosis and Treatment

IQR

inter-quartile ranges

$\mathrm{HF}$

Health Facility WHO:World Health Organization

HIV

Human Immunodeficiency Virus

OR

Odds ratio

RBC

Rwanda Biomedical Center

TB

Tuberculosis

TB\&ORD

Tuberculosis and Other Respiratory Diseases

\section{Declarations}

\section{Conflict of interest declarations}

Authors declare that they have not conflict of interest to publish this manuscript

\section{Ethical approval and consent to participate}

The approval of the study and study instruments were obtained from the National Health Research Committee and the Rwanda National Ethics Committee.

A written signed consent form was provided by participants, they are available in the National Institute of Statistics of Rwanda.

\section{Availability of data}

The data set of this study is available either in Rwanda Biomedical Center or in the National Institute of Statistics of Rwanda 
Patrick Migambi, Augustin Dushime, Murego Felix and Mwumvaneza Mutagoma designed the study, conducted data collection, data analysis and manuscript writing.

Prosper Karame, Muhammed Semakula and Leopold Bitunguhari worked on manuscript writing and review.

Francine Birungi participated in study design and manuscript writing.

Ndishimye Pacifique and Nshimiyimana Ladislas contributed in data analysis and manuscript writing

\section{References}

1. Commar A, Prasad V, D’Espaignet ET. WHO global report on trends in prevalence of tobacco use 2000-2025. 2019. $121 \mathrm{p}$.

2. Unger JB, Cruz T, Shakib S, Mock J, Shields A, Baezconde-Garbanati L, et al. Exploring the cultural context of tobacco use: A transdisciplinary framework. Nicotine Tob Res. 2003;5(SUPPL. 1).

3. Egbe CO, Petersen I, Meyer-Weitz A, Asante KO. An exploratory study of the socio-cultural risk influences for cigarette smoking among Southern Nigerian youth. BMC Public Health. 2014;14(1):19.

4. Magitta NF. Epidemiology of tobacco use and dependence in Sub-Saharan Africa: A systematic review. J Pulmonol Clin Res [Internet]. 2018;2(1):9-15. Available from: http://www.alliedacademies.org/

5. Amere GA, Nayak P, Salindri AD, Narayan KMV, Magee MJ. Contribution of smoking to tuberculosis incidence and mortality in high-tuberculosis-burden countries. Am J Epidemiol. 2018;187(9):184655.

6. Tang S, Bishwajit G. Prevalence of Smoking among Men in Ethiopia and Kenya: A Cross-Sectional Study. 2018;

7. National Institute of statistics. Rwanda Demographic and Health Survey. Rwanda. 2015.

8. Alavi-Naini R, Sharifi-Mood B, Metanat M. Association Between Tuberculosis and Smoking. Int J High Risk Behav Addict. 2012;1(2):71-4.

9. Gegia M, Magee MJ, Kempker RR, Kalandadze I, Chakhaia T, Golub JE, et al. Tobacco smoking and tuberculosis treatment outcomes: A prospective cohort study in Georgia. Bull World Health Organ. 2015;93(6):390-9.

10. Thomas BE, Thiruvengadam K, Rani S, Kadam D, Ovung S, Sivakumar S, et al. Correction: Smoking, alcohol use disorder and tuberculosis treatment outcomes: A dual co-morbidity burden that cannot be ignored (PLoS ONE (2019) 14:7 (e0220507) DOl: 10.1371/journal.pone.0220507). PLoS One. 2019;14(11):1-12.

11. Huang CC, Tchetgen E, Becerra MC, Cohen T, Galea J, Calderon R, et al. Cigarette smoking among tuberculosis patients increases risk of transmission to child contacts. Int J Tuberc Lung Dis. 
2014;18(11):1285-91.

12. Jiménez-Fuentes MÁ, Rodrigo T, Altet MN, Jiménez-Ruiz CA, Casals M, Penas A, et al. Factors associated with smoking among tuberculosis patients in Spain. BMC Infect Dis [Internet]. 2016;16(1):1-9. Available from: http://dx.doi.org/10.1186/s12879-016-1819-1

13. Blecher E, Ross H. Tobacco Use in Africa: Tobacco Control through Prevention. Am Cancer Soc. 2013;

14. Kabwama SN, Ndyanabangi S, Mutungi G, Wesonga R, Bahendeka SK, Guwatudde D. Tobacco use and associated factors among Adults in Uganda: Findings from a nationwide survey. Tob Induc Dis [Internet]. 2016;14(1):1-8. Available from: http://dx.doi.org/10.1186/s12971-016-0093-8

15. Habiyaremye F, Rwunganira S, Musanabaganwa C, Muhimpundu MA, Omolo J. Tobacco use and associated factors among Rwandan youth aged 15-34 years: Findings from a nationwide survey, 2013. PLoS One. 2019;14(10):1-8.

16. Behr J, Nowak D. Tobacco smoke and respiratory disease. World. 2002;58(44):9.

17. Khan AH, Sulaiman SAS, Hassali MA, Khan KU, Ming LC, Mateen O, et al. Effect of smoking on treatment outcome among tuberculosis patients in Malaysia; A multicenter study. BMC Public Health. 2020;20(1):1-8.

18. Louwagie GM, Ayo-Yusuf OA. Tobacco use patterns in tuberculosis patients with high rates of human immunodeficiency virus co-infection in South Africa. BMC Public Health. 2013;13(1):1-10.

19. Wessels J, Walsh CM, Nel M. Smoking habits and alcohol use of patients with tuberculosis at standerton tuberculosis specialised hospital, mpumalanga, south africa. Heal SA Gesondheid. 2019;24:1-6.

20. Allen AM, Scheuermann TS, Nollen N, Hatsukami D, Ahluwalia JS. Gender differences in smoking behavior and dependence motives among daily and nondaily smokers. Nicotine Tob Res. 2016;18(6):1408-13.

21. Loddenkemper R, Brönnecke M, Castell S, Diel R. Tuberculosis and Tobacco Smoking. Pneumologie. 2016;70(1):17-22.

22. Wang Q, Shen JJ, Sotero M, Li CA, Hou Z. Income, occupation and education: Are they related to smoking behaviors in China? PLoS One. 2018;13(2):1-17.

23. Kurgat C. Trends in Cigarette Smoking in Kenya and the Challenges Impeding Cessation. Am J Biol Environ Stat. 2019;5(1):7. 